Eos, Vol. 72, No. 39, September 24, 1991

E O S, T R A N S A C T I O N S, A M E R I C A N G E O P H Y S I C A L U N I O N

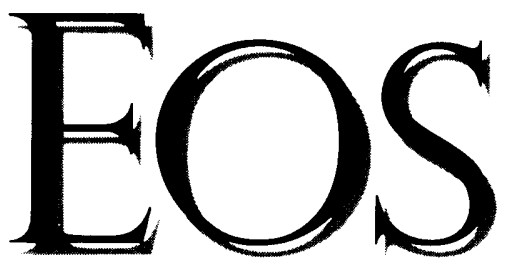

VOLUME 72, NUMBER 39

SEPTEMBER 24, 1991

PAGES 417-424

\section{What Is the Southern California Earthquake Center?}

PAGES 417, 421

Keiiti Aki, Thomas Henyey, and Thomas Heaton
On February 11, Congressman George E. Brown, Jr., Chairman of the House Committee on Science, Space and Technology, together with the National Science Foundation, local officials, helped inaugurate the Southern California Earthquake Center"(SCEC) on the campus of the University of Southern California. SCEC is one of 14 new NSF Science and Technology Centers and includes a substantial commitment from the USGS for FY91. The center is a consortium of seven core academic institutions-USC (coordinating institution), Caltech, Columbia University's Lamont-Doherty Geological Observatory, University of California at Los Angeles, University of California at Santa Barbara, University of California at Santa Cruz, and University of California at San Diego's Scripps Institution of Oceanography-in partnership with the USGS's Office of Earthquakes, Volcanoes, and Engineering (OEVE). The center grew out of an April 3-5, 1989, workshop at Lake Arrowhead, Calif., convened by the USGS to discuss the need for an expanded effort in earthquake research in southern California.

The National Science Board recommended that SCEC be funded at a level of $\$ 13.4$ million over the next 5 years, or approximately $\$ 2.7$ million per year. It was presumed that this would be the NSF commitment. However, as a result of the federal budget compromise for FY91, the NSF Science and Technology Centers Program received a $40 \%$ cut, and SCEC received only $\$ 1.4$ million from NSF this year. At the same time, the USGS component of the National Earthquake Hazard Reduction Program (NEHRP) received a substantial supplement for FY91, and USGS/OEVE was able to help launch the center with a matching grant of

Keiiti Aki and Thomas Henyey, University of Southern California, Los Angeles, CA 90089; Thomas Heaton, U.S. Geological Survey Office of Earthquakes, Volcanoes and Engineering, Pasadena, CA 91106 the U.S. Geological Survey, and state and
$\$ 1.85$ million. USGS support of the center was identified as a priority item in the NEHRP appropriation. The additional NEHRP funding has also permitted OEVE to add \$2.1 million of new monies for internal projects that are a part of SCEC. The largest USGS emphasis will be on the Pasadena office, which was allocated $\$ 820,000$ for new projects, although USGS personnel from Menlo Park, Denver, Reston, and Riverside will also be included in this effort.

The principal task of SCEC will be to focus the intellectual resources of the scientific community on the development of a "master model," based on a combination of existing knowledge of the earthquake process and knowledge to be gained through the application of new technologies and future research. The master model is a frame- work in which all available geoscientific information pertinent to earthquakes in southern California will be integrated in order to develop the methodology for a timespace dependent probabilistic seismic hazard analysis of the region. It will reflect a broad consensus of center scientists that is distilled from the sum of the data and the most current scientific thinking.

SCEC research and intellectual activities will be structured around eight research components of the master model. Groups will be organized to develop each research component, and construction of the master model will be a product of integration by the center through a carefully structured set of group meetings, seminars, and center workshops. Input from the user community will help guide research directions and master model development vis-a-vis its application. A readily accessible data center in Pasadena will archive the master model and all pertinent geophysical and geological data.

SCEC will use seismically active southern California as a natural laboratory in which to develop this next generation of earthquake hazard mitigation methodology. The grave risks posed by major earthquakes certain to occur in urban southern California over the next few decades makes the selection of this region a logical focal point for study. Fur-

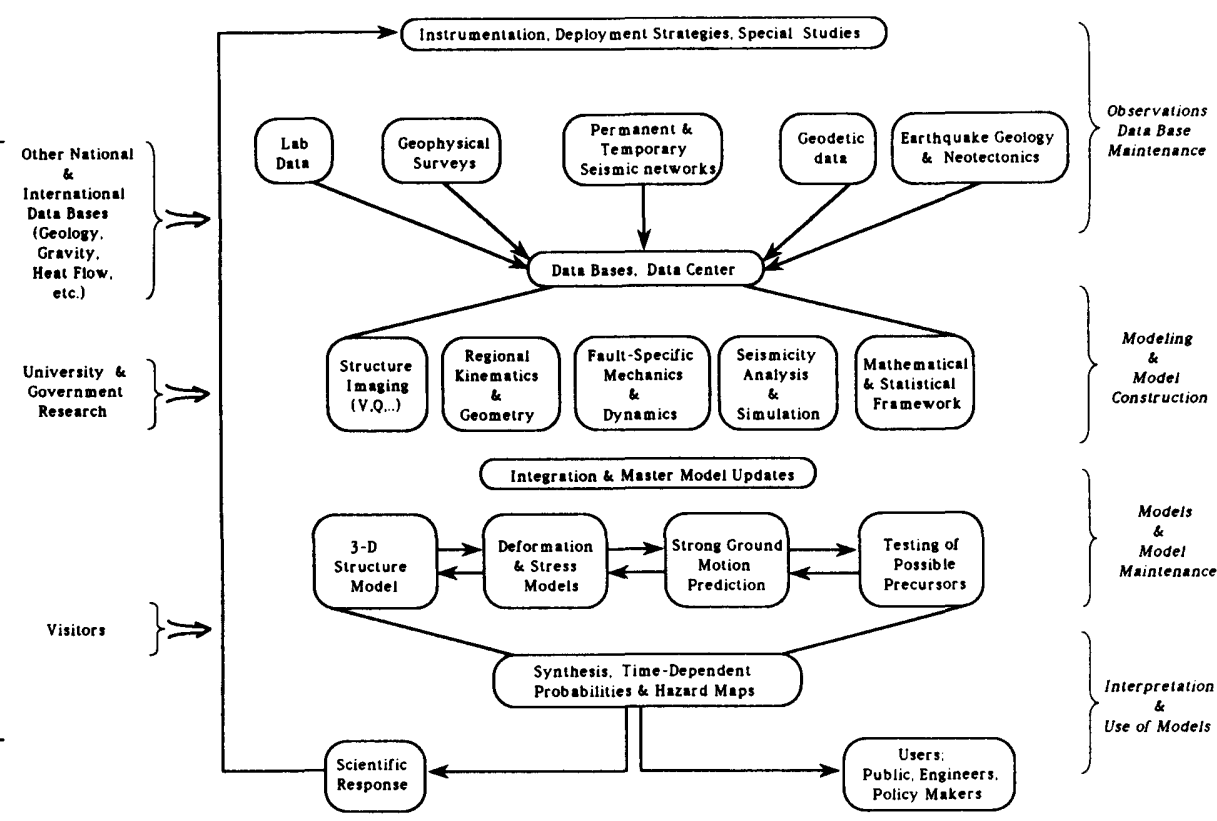

Fig. 1. The master model, showing seismogenic structures and earthquake processes in southern California. 
thermore, California's academic institutions have a history of earthquake research and a technical infrastructure in which to conduct the work. It is only in earthquake-prone areas where application of such methodology can be tested.

\section{Relevance and Intellectual Focus of the Center}

The catastrophic loss of life and property that results from major earthquakes worldwide has been well documented. Within the past 2 decades, nearly half a million lives have been lost and tens of billions of dollars in property destroyed. Reports prepared by the Federal Emergency Management Agency, the National Security Council, and others estimate that losses in Los Angeles alone (from any one of a number of probable magnitude $6+$ to $8+$ earthquakes, such as a repeat of the 1933 Long Beach earthquake), w.ould be between a few billion and $\$ 70$ billion. Estimates of the loss of life range from hundreds to tens of thousands of persons depending on magnitude, epicentral location, and time of day. A sound scientific understanding of the earthquake source-its physical nature and probable location, time of occurrence, and size-and of the resulting radiated seismic wavefield are essential for substantially reducing the risk from future earthquakes.

Perhaps the most unsettling and at the same time most intriguing finding by earthquake scientists over the last decade concerns the timing of large earthquakes on the San Andreas fault. Trenches dug across the fault trace have not only helped to confirm rates of slip based on plate tectonics, but have also permitted precise radiocarbon dating of strata broken by more than a dozen major earthquakes in the last $\sim 3000$ years on the Mojave segment of the fault in south ern California. These results indicate that great earthquakes return on the average every 140 years along this segment and that there is a $60 \%$ probability of a magnitude 7.5 or greater earthquake along the San Andreas fault in southern California within the next 30 years. Thus, there may be a unique opportunity for SCEC to observe events preceding a great earthquake.

Although future great earthquakes are inevitable on the San Andreas fault, little is understood about the nature of the ground motions that will occur in urban areas of southein California. The disastrous collapse of modern, reinforced, high-rise buildings during amplified ground motions in Mexico City at distances larger than $300 \mathrm{~km}$ from the 1985 Michoacan earthquake is a dramatic reminder of the importance of understanding the effects of wave propagation.

There are other major gaps in our understanding of earthquake hazards in southern California. The 1987 Whittier Narrows earthquake (M 5.9) and the 1983 Coalinga earthquake (M 6.5) both involved rupture on buried thrust faults that had no obvious surface traces. Over the past several years, there has been growing concern that an extensive system of active buried thrust faults is located directly beneath metropolitan Los Angeles. It has even been suggested that the geologic structure is similar to that in the southern San Joaquin Valley, where the 1952 Kern County earthquake (M 7.7) occurred. Are such earthquakes to be expected in Los Angeles? The answer to this question dramatically changes estimates of seismic hazard in the region.

SCEC will take full advantage of southern California's natural earthquake hazards' laboratory as represented by a highly complex and populous society at risk along an active plate tectonic boundary. Outreach to the practicing and research engineers, emergency preparedness officials, the media, and the public will complement important new field studies in strong ground motion prediction, regional seismicity, fault zone geology, subsurface imaging, and crustal deformation. The master model will be a product adapted to the needs of the planning and disaster preparedness communities in seismically prone regions.

\section{Master Model}

The principal task of SCEC will be to focus the intellectual resources of the scientific community on the development of the master model. The master model (see Figure 1) will represent a constantly updated scientific representation of seismogenic structures and earthquake processes in southern California. It will be developed into forms applicable to earthquake hazard mitigation in the public and private sectors. For example, in areas where methodologies can be well established, the master model might take the form of maps of three-dimensional seismic velocity distribution, of crustal deformation, or of various characteristics of seismicity. In areas where a diversity of hypotheses and a broad spectrum of opinions exist, such as precursory phenomena, the substance of the master model will be debated in regularly scheduled forums and can be conveyed as such to government officials, for example, who are responsible for information transfer to the public.

SCEC will be structured to develop, refine, and apply (that is, transfer to the user community) the master model on one hand, and acquire and integrate the pertinent data for model improvement on the other. Through appropriate interaction and feedback, the requirements of the master model will guide data acquisition and interpretation. For these purposes, we consider the master model, and thus the center, to be composed of eight research and application components: seismic hazard analysis and master model construction, strong ground motion prediction, fault zone geology, subsurface imaging of seismogenic zones, crustal deformation, regional seismicity, physics of earthquake sources, and engineering applications. When fully integrated, all the research components, except seismic hazard analysis and master model construction, will represent our best understanding of the earthquake process and constitute input to the master model. Research in seismic hazard analysis and master model construction constitutes the output and application component.

The master model will be developed from data bases and their analyses through a structured process involving working groups, seminars, and workshops with participation from the user community. Major center-wide workshops are held twice a year. Group and topical workshops are convened as needed. For example, a workshop on earthquake dynamics was held at UCSB on June 19-21, and a workshop for developing working relationships between seismologists and geotechnical engineers will be held in Pasadena on October 18. Monthly seminars rotate among the participating institutions; the first three were at USC, UCLA, and UCSD, respectively.

Ultimately, the master model will have to be represented in tangible form, that is, in terms of research products. It will include maps of $P$ and $S$ wave velocities for the three principal layers of the lithosphere-the brittle upper crust, the ductile lower crust, and the upper mantle; maps of frequency-dependent seismic attenuation; maps of seismicity parameters such as hypocenters, b-values, clustering, and swarms; maps of the rate of crustal strain and tectonic stress; a map of the probability of damaging earthquakes occurring on major faults for time periods ranging from weeks to decades; a computer library of empirical Green's functions for all possible source-receiver combinations; response spectra and time series of strong ground motion over widespread and diverse regions of southern California; and maps of the probability of ground motion exceeding a prescribed level. In addition, the center will generate many on-line data bases that will be readily accessible to both the research and user communities.

Finally, the center will have two important programs in education and outreach. One program will address the needs of the general public and the primary and second ary schools in southern California. It will be run in conjunction with the Southern California Earthquake Preparedness Project (SCEPP). A second, visitors' program, will permit established researchers and postdoc toral fellows not affiliated with the center to interact for varying lengths of time with center scientists at one or more of the participating institutions. As of this writing, the visitors' program received (in response to a notice in EOS) an enthusiastic welcome from the earthquake hazard community throughout the world. We have just selected our first round of visitors from among 48 applicants representing 16 countries.

\section{The Center and California Quake Funding}

The decision by the NSF Science and Technology Center's Program and the USGS to launch SCEC has provided some important benefits for the seismological community, principally in southern California. First, 
Table 1. Academic Colnvestigators, 1991

Institution

Researcher

Core Institutions

University of Southern California (Coordinating Institution)

California Institute of Technology

Lamont-Doherty Geological Observatory

University of California, Los Angeles

University of California, San Diego

University of California, Santa Barbara

University of California, Santa Cruz

Participating Institutions

University of California, Riverside

University of Nevada, Reno

San Diego State University

•

Harvard University

Stanford University

Massachusetts Institute of Technology

Princeton University

Oregon State University

\section{Stephen Park}

John Anderson, Steven Wesnousky

Steven Day, Thomas Rockwell

James Rice

Allin Cornell

Bradford Hager

John Suppe

Robert Yeats

Industry Participants

Crouch, Bachman Associates, Inc.

James Crouch

Davis and Namson, Consulting Geologists

Thom Davis lines of research. This issue has been debated by the center, and we believe that we have adopted the correct approach for at least the first year or two for the reasons discussed below.

First, a primary early goal of the center is the integration of existing data and ideas developed over the last 25 years of earthquake-related research in southern California, and the development of an initial master model. This requires participation by the many individuals responsible for, or familiar with, the appropriate information. Modest funding from the center will both encourage and enable those individuals to participate in the data integration and formulation of an initial master model.

Second, the center is broad and needs to maintain a critical mass in each one of its research components unless, of course, we drop one or more of these components in order to concentrate on the remaining ones. While this might be a long-term strategy, it seems to us that in the early going, breadth is one of the center's strengths. In effect, with only a small amount of incremental funding to each of a number of individual investigators, the center will be able to leverage a relatively large return of data, analysis, and ideas.

And third, it is not clear who the productive players are going to be in the long run. Productivity vis-a-vis the center means more than doing good basic research. It means a commitment to the goals and products of the center, to interaction and participation in master model development, and to timely completion of research agendas and other center tasks without constant harassment from the center directors. Thus, the firstyear's funding is not a guarantee of longterm support at some incremental level, but rather an invitation to join the center and its mission.

\section{Center Management}

The center is managed by a science dijeopardized. This has concerned SCEC, NSF, and USGS to the extent that we are working jointly to establish a proposal coordination mechanism in order to structure a balanced earthquake research program for southern California. Thus, reviewers of noncenter proposals for earthquake research in southern California can emphasize the scientific merit and relevance of these proposals as usual.

Virtually no SCEC participating scientist is currently receiving sufficient support from the center to maintain his/her research program independently of other funding sources. Of the $\$ 3.25$ million that the academic component of the center is receiving the first year, $\$ 1.8$ million is being used to enhance the general infrastructure for earthquake research in southern California (for example, data center, portable instruments, GPS monumentation, etc.), and the remaining $\$ 1.45$ million is being divided among $\sim 50$ researchers (see Table 1 ). This may seem to be too widespread a distribution of the limited resources - cutting the pie into a large number of rather insignificant pieces and a failure to focus on particularly fruitful rector, an executive director, and a board of directors. The board of directors is the primary governing body of the center. It is responsible for selection of officers, development of the annual science plan and other center policy, and monitoring the progress of the center. The board is comprised of one person from each of the seven core academic institutions and one person from the USGS who are selected by the their respective deans or directors. The science director is responsible for final scientific and directional oversight, final distribution of resources, and master model development. $\mathrm{He} / \mathrm{she}$ must be a member of the board and, in fact, chairs that body. The executive direc tor is responsible for the day-to-day operation of the center and sits on the board as an ex-officio member. Individual group leaders coordinate the planning and scientific activities of each of the eight research components. K. Aki and T. Henyey have been designated as science director and executive director, respectively. Current members of the board include Aki, USC (chairman); R. 
Clayton, Caltech; L. Seeber, Lamont-Doherty; D. Jackson, UCLA (vice chairman); R. Archuleta, UC Santa Barbara; K. McNally, UC Santa Cruz; B. Minster, Scripps; and T. Heaton, USGS. Information about the center, including its visitors' program, can be obtained by contacting Denise Steiner, Southern California Earthquake Center, University of Southern California, University Park, Los Angeles, CA 90089; fax 213-740-0011.

\section{New EOS Payload Proposed}

\section{PAGES $417-418$}

Scientists working on NASA's Earth Observing System (EOS) are now considering a new set of instruments for the global monitoring program and debating the order in which these should fly.

"In this time of uncertain budgets, what we have to do as a scientific community is to prioritize our measurements," said Jeff Dozier, EOS project scientist, at a NASA press workshop September 12. "This allows us to give to the Congress and the administration a program they can buy by the yard."

Dozier has crafted what he emphasizes is a "straw man" payload for the EOS team to mull over, based on discussions in August by the project's investigator working group. "This is not the payload," he cautioned. "What I think is going to happen is that we'll have a payload that looks something like this." The EOS payload panel will meet October 21-24 in Easton, Md., to make formal recommendations on the program's instrument and science priorities to NASA associate administrator for space science and applications Lennard Fisk.

Of the proposed instruments, the first group would be launched on two or three satellites over about two years, beginning in 1998. In alphabetical-not priority-order, these are: AIRS (an improved atmospheric sounder); ASTER (a Japanese instrument that makes high-resolution surface measurements); CERES (measures the Earth's radiation balance); HIRDLS (measures ozone, methane, and the temperature structure of the stratosphere); MIMR (a microwave radiometer to measure surface characteristics); MISR (a multi-angle radiometer to measure aerosols, cloud properties, and the multidirectional aspect of surface reflectance); MODIS-N (an instrument for globally mapping an array of properties); MOPITT (measures carbon monoxide and methane in the troposphere); and SAGE III (measures aerosols and some atmospheric gases).

The next payload priority is ocean color instruments, which means the continuation of SeaWiFS and the establishment of data links to OCTS and MERIS. A new instrument of this type does not rank at the top of the EOS list, Dozier says, because several are already being built by the Japanese, Europeans, and others. For budget reasons, "we're looking at where we can depend on the foreign partners," he explained.

Ranked third are two instruments that measure solar output-ACRIM and SOLSTICE. It is not necessary for these instruments to fly on an EOS platform, although they may do so; in any case, they will be launched as the opportunity arises. Next come special platforms with ALT/GGI (an altimeter and a Global Positioning System instrument) and TES (to monitor tropospheric emissions), followed by provisions for a scatterometer if plans for the European version fall through. U.S. scientists are concerned about whether the European instrument will work, because it operates on a different frequency than the proposed U.S. instrument.

A laser altimeter, ranked next, will resolve the question of whether Greenland and Antarctica are growing or shrinking. This is followed by two expensive instruments, LAWS (to measure atmospheric circulation) and SAR (for hydrological and ecological studies). EOS scientists are hoping for technological breakthroughs that will reduce the costs of these instruments. Next come instruments for measuring stratospheric chemistry. Dozier notes that scientists disagree over what exactly should be studied in the middle and upper stratosphere, so the instruments will be identified after data from the recently launched Upper Atmosphere Research Satellite are examined. Last on the priority list, because other instruments already provide redundancy, is an ocean-color spectrometer.

"This is a critical time for EOS," Dozier says. "Decisions of the next few months will shape Earth observations for the next decade and beyond. The budget profile and runout are uncertain, but even the lower bounds should enable us to make substantial progress on the high priority issues."-Lynn Teo Simarski

\section{Weather Data Gap Problem Resolved}

\section{PAGE 418}

It looks as though the United States will avoid the crisis situation of a gap in weather data resulting from the aging GOES-7 satellite and technical problems with the next generation of weather satellites (GOESNEXT). Officials at the National Oceanic and Atmospheric Administration, which oversees the National Weather Service, recently announced their decision to borrow at least one and possibly several European satellites until the GOES-NEXT program gets off the ground.

The GOES (Geostationary Operational Environmental Satellites) series is currently 3 years behind schedule and $\$ 500$ million over budget. Problems with its complex design, program management by both NOAA and the National Aeronautics and Space Administration and poor performance by the contractor led Department of Commerce Secretary Robert Mosbacher to slow down the GOES-NEXT series to ensure that it is built right.
NOAA's decision to borrow Meteosat-3, one of the European Space Agency's spare satellites, came after months of investigation and Congressional examination, during which NOAA explored several options. They looked into buying a satellite being built in the United States by Hughes for Japan, building a clone of GOES-7, and continuing ahead with the GOES-NEXT program, hoping that GOES-7 does not fail before completion of the project.

NOAA undersecretary for oceans and atmospheres John Knauss said the agency concluded that borrowing a European satellite would be their best option, according to the New York Times. NOAA ruled out the other options because the Japanese will need their new satellite to replace the current one, and it would take at least 3 years to build a new GOES satellite, which would not be enough time to ensure against a gap in weather data.

By borrowing the satellite, the United States would be continuing a "long-standing exchange of meteorological information" with the Europeans, said Frank LePore, an NOAA public affairs specialist. In 1985 , the United States lent GOES-4 to the Europeans for extra data support. The European agencies Eumetsat (European Meteorological Satellite Consortium) and ESA are currently in negotiation with NOAA to decide the fine points of the agreement, such as the location of the satellite and the length of agreement.

Meteosat- 3 is currently at $50^{\circ} \mathrm{W}$ longitude and is giving good hurricane coverage for the eastern United States, said LePore. It may be moved an additional $48^{\circ}$ to $90^{\circ} \mathrm{W}$, where GOES-7 is positioned. Borrowing the European satellite will not be free for the United States, however. In order to communicate with Meteosat-3, the United States will have to construct some new ground equipment for interpreting the data. A $\$ 10$ million facility will be built at Wallops Island, Va., for this purpose.

Negotiations will continue through midOctober, and according to LePore, "early indications are that there are no objections in making Meteosat-3 available to the United States."

Some members of Congress are pleased with the Commerce Department's decision to slow development of the GOES-NEXT series. Howard Wolpe (D-Mich.), chairman of the Subcommittee on Investigations and Oversight of the House Science Committee, said "In choosing to do GOES-I right, Secretary Mosbacher made a prudent decision. We may finally be seeing a break in the schedule-driven fever that has crippled the GOESNEXT program all along." Late this summer the subcommittee determined that NASA had underestimated its technical challenges in the satellite program and overestimated their contractor's ability to deliver the product on time and at cost. Sherwood Boehlert (RN.Y.), ranking member of the subcommittee, said "I am glad NOAA has stopped gambling on NASA's advice."

In a letter to Mosbacher in August urging him to slow GOES-NEXT, Wolpe said, "We will continue our oversight of this important 